\title{
The Welfare Effects of Use-or-Lose Provisions in Markets with Dominant Firms
}

\author{
Ian Gale and Daniel P. O'Brien*
}

August 15, 2012

\begin{abstract}
A use-or-lose provision requires that firms employ a certain minimum fraction of their productive capacity. Variants have been used by regulators in the airline and wireless communications industries, among others. A typical stated objective is to limit capacity hoarding, thereby increasing aggregate output and welfare. When the dominant firm is more efficient than fringe firms, we find that imposing a use-or-lose provision induces the dominant firm to acquire capacity from the fringe, which causes aggregate output to fall. When the dominant firm is less efficient than the fringe, aggregate output rises. In both cases, total surplus may rise or fall. (JEL D42, L12, L51.)
\end{abstract}

KEYWORDS: Dominant firm, use-or-lose provision, capacity acquisition.

*Gale: Department of Economics, Georgetown University, 3700 O St., NW, Washington, DC 20057 (e-mail: galei@georgetown.edu). O’Brien: U.S. Federal Trade Commission, 601 New Jersey Ave., NW, Washington, DC 20580 (e-mail: dobrien@ftc.gov). The authors thank Josh Gans, Ken Hendricks, Dan Hosken, Simon Loertscher, and Chris Metcalf for helpful comments. The views expressed are those of the authors and do not necessarily reflect those of the Federal Trade Commission. 
In an industry with scarce capacity, a firm may benefit from leaving some of its capacity idle and keeping output below the socially optimal level. If rival firms are capacity constrained, they may be unable to expand and offset the output reduction. This situation could arise for several reasons. Aggregate capacity may be limited by infrastructure, leaving individual firms with little ability to expand. In the airline industry, for example, capacity is limited by the number of runways and gates. Capital may also be lumpy or subject to large increasing returns to scale, making it uneconomical for an individual firm to expand its capacity. A firm's capacity may also be fixed by exogenous technical factors, as with radio spectrum. In all of these cases, there may be some ability to increase capacity through improvements in technology, but it is limited in the short run.

Antitrust and regulatory authorities have historically been concerned with two possible inefficiencies in industries with scarce capacity. One is the standard welfare loss that occurs if a firm is dominant and restricts output. A second possibility is that trading of capacity may not enhance welfare. Suppose that a dominant firm wishes to purchase capacity from a higher-cost fringe firm. Society would benefit from shifting production to a lower-cost firm, all else equal, but the dominant firm may hold some of the acquired capacity idle. ${ }^{1}$ In several industries with scarce capacity, regulators have imposed useor-lose provisions, which require that each firm utilize a certain minimum fraction of its capacity. All else equal, use-or-lose provisions encourage dominant firms to increase output and they constrain output reductions following capacity acquisitions. In this paper, we study the welfare consequences of employing such provisions.

Many industries have been subject to use-or-lose provisions. The U.S. Federal Aviation Administration (FAA) requires airlines at certain high-density airports to use their takeoff and landing slots a minimum percentage of the time. ${ }^{2}$ Similarly, the U.S. Federal Communications Commission (FCC) has enforced "loading" requirements for some wireless

\footnotetext{
${ }^{1}$ Antitrust or regulatory authorities often block acquisitions by dominant firms if the cost savings are too small to counter the projected output restriction. This remedy is not ideal, however, as it prevents capital movements that could reduce industry costs.

2 "Slots" are essentially rights to take-off and land over some period of time.
} 
communication services to prevent hoarding of radio spectrum. For example, mobile radio operators faced a minimum-use requirement per channel. (See 47 C.F.R. Part 90, 631 (Oct. 1, 2001).) Water rights, mineral leases, and fishing quotas have also been subject to use-or-lose provisions.

The history of capacity regulation in the airline industry sheds light on the issues surrounding use-or-lose provisions. In 1969, the U.S. Federal Aviation Administration (FAA) established the High Density Rule (HDR), which limited the number of take-offs and landings during certain hours at Kennedy, LaGuardia, Newark, O'Hare and Washington National Airports. ${ }^{3}$ The HDR created take-off and landing slots to allocate supply.

The HDR initially allocated slots through unanimous agreement by a committee of air carriers. This system was cumbersome and the FAA recognized that the committees were not "functioning in a manner which provides for the efficient allocation of slots for rapid adjustment to market conditions and shifting carrier needs and preferences, for adequate opportunity for expansion of operations, or for new carriers to serve high density airports." 4 In 1985, the FAA addressed the inefficiencies by adopting the "buy-sell rule," which allowed carriers to buy, sell, or lease slots, and imposing a use-or-lose provision that required carriers to use slots at least 65 percent of the time over a two-month period or have them withdrawn and reallocated. The FAA adopted the rule "to permit maximum reliance on market forces to determine the slot distribution," adding that the rule "minimizes the need for government intervention in the continuing allocation and distribution of slots." 5 Regarding the use-orlose provision, the FAA noted that most commenters supported the provision, citing the need to "prevent large carriers or several large carriers from 'hoarding' slots in an attempt to restrict service to drive up fares or to keep smaller competitors from entering into or expanding in certain markets." ${ }^{6}$ In other words, there was concern that airlines might find it profitable to restrict their own output, or they might hoard capacity to keep rivals from

\footnotetext{
${ }^{3}$ See Federal Aviation Regulations Amendment No. 93-13, 33 Fed. Reg. 17896 (December 3, 1968).

${ }^{4} 50$ Fed. Reg. 52181 (December 20, 1985).

${ }^{5} \mathrm{Op}$. cit., 52184.

${ }^{6}$ Op. cit., 52188.
} 
expanding output.

In 1992, the FAA increased the usage requirement to 80 percent, stating that "[t]his higher percentage should encourage carriers to hold no more slots than their markets demand, potentially freeing up underutilized slots for use by other carriers without imposing impractically stringent use requirements." 7 The details of slot allocation rules have changed over the years, but the two essential features - slot trading and use-or-lose provisionsremain, as does the FAA's justification for use-or-lose provisions. ${ }^{8}$

We study the use of a use-or-lose provision in a market with a dominant firm and a capacity-constrained fringe. The firms are permitted to buy and sell capacity before production takes place. To our knowledge, this paper is the first to study the combination of restrictions on capacity usage and the ability of firms to buy and sell capacity.

As suggested above, one might expect that imposing a use-or-lose provision would induce a firm with excess capacity either to increase its output or to sell some of its capacity in order to come into compliance. Such strategies would raise aggregate output and lower price. An alternative compliance strategy goes in the opposite direction: Purchasing capacity from the fringe and using it in production increases the fraction of the dominant firm's capacity that is used. This turns out to be a more profitable way to comply with the constraint, so the dominant firm is more likely to purchase capacity when a use-or-lose provision is in force. If the dominant firm and fringe firms have equal marginal costs, a use-or-lose provision will induce the dominant firm to purchase exactly the amount of capacity needed to leave aggregate output at the pre-regulation level. If the dominant firm has a cost advantage, it will acquire even more capacity, which reduces aggregate output. In other words, far from inducing the dominant firm to divest itself of idle capacity, the provision may induce the firm to purchase enough capacity that aggregate output falls. Moreover,

\footnotetext{
${ }^{7} 57$ Fed. Reg. 37310 (August 18, 1992).

${ }^{8}$ The 80 percent threshold remains in effect as of this writing. See 14 C.F.R. Part 93.227. In a 2005 Notice of Proposed Rulemaking for dealing with congestion issues at O'Hare airport, the FAA reiterated that in the absence of use-or-lose provisions "carriers could hoard existing authorizations to increase the value of their holdings or simply to deprive competitors of greater access to the airport." $70 \mathrm{Fed}$. Reg. 15528 (March 25, 2005).
} 
total surplus may fall if the dominant firm's cost advantage is not large.

Firms often become dominant precisely because they are more efficient than fringe firms, so most of our attention is on that case. But, suppose that the dominant firm were less efficient than the fringe firms. The dominant firm would then have an incentive to sell capacity to the fringe in the absence of a use-or-lose provision. Although a binding use-orlose constraint may still induce the dominant firm to buy capacity, the firm would raise its output by enough to increase aggregate output. Total surplus may fall again, however.

In many cases in which capacity hoarding is a concern, there are multiple firms with market power. When we extend our analysis to oligopoly with a competitive fringe, the results are similar to those with a single dominant firm. For instance, the firms are more likely to acquire capacity when there is a binding use-or-lose constraint than when not. If the constraint binds on all of the oligopolists, and if they have lower marginal costs than the fringe, total output falls when the constraint is tightened. If the oligopolists have higher marginal costs than the fringe, total output rises when the use-or-lose constraint is tightened. The impact on total surplus can go either way.

Similar issues regarding capacity usage arise in the antitrust context. Merger guidelines in the U.S. and Europe discuss the potential anticompetitive effects of mergers when rival firms face capacity constraints. For instance, the U.S. Guidelines observe that a merged firm "may find it profitable unilaterally to raise price and suppress output," and that this effect is more likely if "rival firms face binding capacity constraints that cannot be economically relaxed." 9 Over the years, numerous mergers in both jurisdictions have been allowed to go through on the condition that the merged firm divest (or supply) capacity to rival firms, thereby offsetting the potential harm from the merger. ${ }^{10}$ These divestitures can be thought of as use-or-lose provisions applied to the acquired capacity and fulfilled by the buyers of divested assets.

\footnotetext{
${ }^{9}$ U.S. Merger Guidelines, Section 2.22. See also European Commission Merger Guidelines, 934 .

${ }^{10}$ See, for example, FTC (1999), Massimo Motta, Michele Polo, and Helder Vasconcelos (2002), European Commission (2005), and Penelope Papandropoulos and Alessandro Tajana (2007).
} 
The remainder of the paper is organized as follows. Section I develops a model of capacity acquisition by a dominant firm and analyzes the benchmark case with no useor-lose provision in force. Section II introduces the use-or-lose provision and examines its effects. Welfare implications are investigated in Section III. The case of oligopoly is considered in Section IV. The related literature is discussed in Section V, and concluding remarks are in Section VI.

\section{The Basic Model}

A market has a dominant firm and a competitive fringe. The dominant firm has a marginal cost of $c$ up to its capacity, $k$. Each unit of capacity enables a firm to produce one unit of output. The dominant firm is unconstrained in that its desired output is no greater than $k$. The fringe consists of a continuum of firms with marginal cost equal to $c_{f}$ up to their individual capacities. ${ }^{11}$ Each fringe firm is small enough to be considered a price-taker. Aggregate capacity for the fringe equals $f .^{12}$ Inverse demand for the good is given by a strictly decreasing function, $P(\cdot)$, with a finite choke price.

The firms have the opportunity to buy or sell capacity before production takes place. We model capacity acquisition and production decisions as a three-stage game. In the first stage, the dominant firm announces how much capacity it wishes to buy or sell. Next, the fringe firms decide individually whether to trade with the dominant firm at the marketclearing price for capacity. Finally, in the third stage, the dominant firm and the fringe firms choose their outputs.

We look for a subgame-perfect Nash equilibrium. At the production stage, the dominant firm will choose a quantity to maximize its profit, given the fringe output. (Fringe behavior is straightforward since price-takers will produce up to capacity as long as the output price

\footnotetext{
${ }^{11}$ Although capacity is homogeneous, the dominant firm and fringe may differ in their costs of using it.

${ }^{12} \mathrm{We}$ assume that $k$ and $f$ are large enough that there is an interior solution. If the dominant firm is capacity constrained in equilibrium, the outcome is effectively perfectly competitive and a use-or-lose provision has no effect. If the dominant firm acquires all fringe capacity in equilibrium, tightening a use-or-lose constraint further can only increase output.
} 
exceeds $c_{f}$, which we assume.) At the acquisition stage, purchase and sale decisions must be optimal, given the anticipated behavior at subsequent stages.

\section{A. The Benchmark Case}

We begin the analysis with the case in which there is no use-or-lose provision. This scenario provides context and motivation for the imposition of a use-or-lose provision. Let $x$ denote the dominant firm's net purchase of capacity from the fringe. The firm's profit from production is then

$$
\pi(x) \equiv \max _{0 \leq q \leq k+x} P(q+f-x) q-c q,
$$

since the fringe will produce $f-x$. The following assumption guarantees that the profitmaximizing quantity is unique.

Assumption $1 P(q+f-x) q-c q$ is strictly quasi-concave for $q \in(0, k+x)$, for any given $x \in(-k, f)$.

This assumption, which holds if the dominant firm's marginal revenue is strictly decreasing, ensures that the firm's profit function is single-peaked for any level of capacity acquisition.

The first-order condition for an interior solution takes the form

$$
P^{\prime}(q+f-x) q+P(q+f-x)-c=0
$$

for given $x{ }^{13}$ The second-order necessary condition is:

$$
P^{\prime \prime}(q+f-x) q+2 P^{\prime}(q+f-x) \leq 0 .
$$

Let $q(x)$ denote the profit-maximizing quantity.

To see how $q(x)$ depends on $x$, differentiate the first-order condition with respect to $x$. This yields

$$
q^{\prime}(x)=\frac{P^{\prime \prime}(q+f-x) q+P^{\prime}(q+f-x)}{P^{\prime \prime}(q+f-x) q+2 P^{\prime}(q+f-x)}=1-\frac{P^{\prime}(q+f-x)}{P^{\prime \prime}(q+f-x) q+2 P^{\prime}(q+f-x)} .
$$

\footnotetext{
${ }^{13}$ We assume that the dominant firm does not end up constrained, which means that it does not sell a large amount of capacity. The dominant firm will only sell a large amount of capacity if the fringe firms are much more efficient.
} 
The denominator is negative so $q^{\prime}(x)<1$. If the dominant firm acquires one additional unit of capacity, it will use the fraction $q^{\prime}(x)$ and leave the remaining $1-q^{\prime}(x)$ idle.

Now turn to the acquisition stage, and consider the relationship between the acquisition price and the amount of capacity acquired. The dominant firm announces the quantity that it will buy or sell. The fringe firms then decide individually whether to trade with the dominant firm.

Suppose that the dominant firm acquires $x$ units of capacity from the fringe. Aggregate output will then be $q(x)+f-x$. Let $b(x) \equiv P(q(x)+f-x)-c_{f}$ be the price-cost margin of a fringe firm when the dominant firm acquires $x$ units of capacity and then produces $q(x)$. Since $b(x)$ equals the value of a unit of capacity to a fringe firm, it is the market-clearing price of capacity. ${ }^{14}$

Let

$$
\Phi(x) \equiv \pi(x)-b(x) x=[P(q(x)+f-x)-c](q(x)-x)+\left(c_{f}-c\right) x
$$

denote the dominant firm's profit from acquiring $x$ units at the market-clearing price and then selecting the profit-maximizing output. ${ }^{15}$ The capacity-acquisition problem amounts to the following:

$$
\max _{-k \leq x \leq f} \Phi(x)
$$

We make one additional assumption.

Assumption 2 The profit from capacity acquisition, $\Phi(x)$, is strictly quasi-concave. ${ }^{16}$

Henceforth, we assume that Assumptions 1-2 hold.

\footnotetext{
${ }^{14}$ If the price of capacity were $b<b(x)$, firms that sold would have been better off not selling. If the price were $b>b(x)$, those that did not sell would have been better off selling. The fringe firms are indifferent if $b=b(x)$ so the market-clearing price is $b(x)$ if the dominant firm buys $x$ units.

${ }^{15} \mathrm{We}$ are implicitly assuming that the dominant firm will only acquire capacity once. It is conceivable that, having made a single purchase at $b(x)$, the firm would have an incentive to purchase again. The dominant firm could commit not to purchase again by using a most-favored customer clause. Alternatively, one could construct a dynamic equilibrium analogous to that in Lawrence M. Ausubel and Raymond J. Deneckere (1989), where a seller lacking commitment gets essentially the same profit as with commitment.

${ }^{16}$ If $P(\cdot)$ is linear, for example, $\Phi(\cdot)$ is strictly concave.
} 
The rate of change of the profit from capacity acquisition is

$$
\Phi^{\prime}(x)=\pi^{\prime}(x)-b(x)-b^{\prime}(x) x .
$$

The purchase of an additional unit of capacity increases the profit from production by $\pi^{\prime}(x)$, it costs $b(x)$, and it drives up the price of inframarginal units by $b^{\prime}(x)$. Using (5) and the first-order condition for production, (2), we can express the first-order condition for capacity acquisition as

$$
\Phi^{\prime}(x)=\left[1-q^{\prime}(x)\right] P^{\prime}(q(x)+f-x) x+c_{f}-c=0 .
$$

This condition yields the first proposition.

Proposition 1. The dominant firm buys (sells) capacity if its marginal cost of production is lower (higher) than the fringe firms'. If marginal costs are equal, no capacity is traded.

Proof. Evaluating (8) at $x=0$, we see that $\Phi^{\prime}(0)>(<) 0$ if $c_{f}>(<) c$, and $\Phi^{\prime}(0)=0$ if $c_{f}=c$. The result then follows from the strict quasi-concavity of $\Phi$.

To get some intuition, suppose that marginal costs are equal. If the dominant firm purchases one unit of capacity, it will use some amount $q^{\prime}$ for production and hold $1-q^{\prime}$ idle. The cost of acquiring the $q^{\prime}$ units is $\left(P-c_{f}\right) q^{\prime}=(P-c) q^{\prime}$, since the price of capacity is the fringe's margin and the marginal costs are equal. The benefit from the $q^{\prime}$ units of production is also $(P-c) q^{\prime}$ since the dominant firm earns $P-c$ on each unit sold. The cost of acquiring the $1-q^{\prime}$ units that will be held idle is $(P-c)\left[1-q^{\prime}\right]$, and the benefit is $-P^{\prime} q\left[1-q^{\prime}\right]$, the additional revenue from the inframarginal units of output, which results from lowering aggregate output by $1-q^{\prime}$. The net effect is $-\left(P+P^{\prime} q-c\right)\left[1-q^{\prime}\right]$, which equals zero because the dominant firm chose the original quantity to maximize profit, so a marginal reduction in $q$ has no first-order effect. It follows that the dominant firm receives no first-order gain from buying a unit of capacity when $c=c_{f}$.

A rise in $c_{f}$ lowers the acquisition price, all else equal. Then, a dominant firm that is more efficient than the fringe will buy capacity. By the same logic, a dominant firm that is less efficient than the fringe will sell. 
One possible rationale for employing use-or-lose provisions is to ensure that capacity acquisitions increase consumer and total surplus. To assess whether this happens, we must first study the impact of capacity acquisitions in the absence of use-or-lose provisions. The impact on consumer surplus is straightforward. Aggregate output is $Q(x) \equiv q(x)+f-x$, which is decreasing in $x$ since $q^{\prime}(x)<1$. In the absence of a use-or-lose provision, any capacity acquisition by an unconstrained dominant firm will reduce consumer surplus. In particular, if the dominant firm is more efficient than the fringe, it will acquire $x>0$, and consumer surplus will fall.

Total surplus is

$$
T S(x) \equiv \int_{0}^{q(x)+f-x} P(z) d z-c q(x)-c_{f}[f-x] .
$$

The derivative with respect to $x$ is

$$
T S^{\prime}(x)=[P(q(x)+f-x)-c]\left[q^{\prime}(x)-1\right]+c_{f}-c .
$$

This yields the following proposition.

Proposition 2. In the absence of a use-or-lose provision: A) Any capacity acquisition by the dominant firm reduces consumer surplus; and B) fixing $c_{f}$, there exists $\underline{c}<c_{f}$ such that the dominant firm's equilibrium capacity acquisition reduces total surplus if $c \in\left(\underline{c}, c_{f}\right)$.

Proof. Part A follows from the discussion in the preceding paragraph. To establish part B, first note that the dominant firm purchases a positive amount of fringe capacity if $c<c_{f}$, by Proposition 1. From (10), $T S^{\prime}(x)<0$ if $c_{f}=c<P(q(x)+f-x)$. More generally, $T S^{\prime}(x)<0$ if $P(q(x)+f-x)\left[q^{\prime}(x)-1\right]+c_{f}<c q^{\prime}(x)$. It follows that there exists an interval, $\left(\underline{c}, c_{f}\right)$, such that capacity acquisitions reduce total surplus if $c$ falls in this interval.

Proposition 2 implies that there is a range of cost parameters over which the transfer of capacity to the dominant firm would be socially efficient if authorities could mitigate the dominant firm's incentive to restrict output. 


\section{Imposition of a Use-or-Lose Provision}

We now examine use-or-lose provisions in a market with a dominant firm. The use-or-lose provision takes the following form here:

Condition UL If a firm has $\tilde{k}$ units of capacity, its output must satisfy $q \geq \alpha \tilde{k}$, where $\alpha \in(0,1)$.

The UL provision requires that the firm employ at least the fraction $\alpha$ of its capacity. ${ }^{17}$ Fringe firms produce up to capacity anyway, so the provision will not have a direct effect on their output.

When UL binds, the dominant firm's output solves the following problem:

$$
\max _{q \geq \alpha(k+x)}[P(q+f-x)-c] q .
$$

At the capacity acquisition stage, the price of capacity is again the fringe's margin, $P-c_{f}$.

The dominant firm will now buy fringe capacity if $c=c_{f}$ and UL binds. When the UL constraint binds, the dominant firm would produce $q=\alpha k$ absent any acquisition. Now suppose that the firm purchases one unit of capacity. Since UL binds, it will use the capacity to produce $\alpha$ more, and it will keep $1-\alpha$ idle. The cost of acquiring the $\alpha$ units is $\left(P-c_{f}\right) \alpha=(P-c) \alpha$, and the benefit from the $\alpha$ units of production is also $(P-c) \alpha$. The cost of acquiring the $1-\alpha$ units that will be held idle is $(P-c)[1-\alpha]$, and the benefit is $-P^{\prime} q[1-\alpha]$, the additional revenue from the inframarginal units of output. The net effect is $-\left(P+P^{\prime} q-c\right)[1-\alpha]$. This expression exceeds zero since $q$ exceeds the unconstrained profit-maximizing quantity here. We conclude that there is an incentive to buy capacity when marginal costs are equal and UL binds.

We now examine formally the impact of imposing and tightening a UL provision. We will see that the dominant firm is more likely to acquire capacity when a binding UL provision is in place than when not. Rather than providing an incentive to sell excess capacity to come into compliance, the UL provision actually strengthens the incentive to

\footnotetext{
${ }^{17}$ The regulator observes capacities and outputs so the constraint is enforced perfectly.
} 
acquire capacity.

A change of variables simplifies the analysis. Let $y \equiv \alpha(k+x)-x$ denote the "variable component" of output when the UL constraint binds and the dominant firm acquires $x$ units. Aggregate output is $\alpha(k+x)+f-x=y+f$, so $y$ is the dominant firm's net impact on output, and the acquisition can be expressed as $x=\frac{\alpha k-y}{1-\alpha}$. The dominant firm's profit can therefore be written as

$$
[P(y+f)-c] \alpha(k+x)-\left[P(y+f)-c_{f}\right] x=[P(y+f)-c] y+\left(c_{f}-c\right) x .
$$

The firm earns the price-cost margin on the variable component of output, with an adjustment for the difference in marginal cost. Substituting for $x$ and rearranging, (12) becomes

$$
P(y+f) y-\frac{c_{f}-\alpha c}{1-\alpha} y-\frac{c-c_{f}}{1-\alpha} \alpha k .
$$

We now have the capacity-acquisition problem:

$$
\max _{k \geq y \geq \alpha k-(1-\alpha) f} P(y+f) y-\frac{c_{f}-\alpha c}{1-\alpha} y-\frac{c-c_{f}}{1-\alpha} \alpha k .^{18}
$$

The first-order condition for an interior solution is

$$
\phi\left(y, \alpha, c, c_{f}\right) \equiv P^{\prime}(y+f) y+P(y+f)-\frac{\left(c_{f}-\alpha c\right)}{1-\alpha}=0,
$$

and the second-order necessary condition is

$$
P^{\prime \prime}(y+f) y+2 P^{\prime}(y+f) \leq 0
$$

Let $y(\alpha) \equiv \alpha(k+x(\alpha))-x(\alpha)$ denote the equilibrium value of $y$. Totally differentiating (15) with respect to $\alpha$ yields

$$
y^{\prime}(\alpha)=\left.\frac{-\phi_{\alpha}}{\phi_{y}}\right|_{y=y(\alpha)}=\frac{\frac{c_{f}-c}{(1-\alpha)^{2}}}{P^{\prime \prime} y+2 P^{\prime}}=\frac{c_{f}-c}{(1-\alpha)^{2}\left(P^{\prime \prime} y+2 P^{\prime}\right)} .
$$

We now summarize how the UL constraint affects aggregate output.

\footnotetext{
${ }^{18}$ The upper bound on purchases is $x=f$, which gives $y=\alpha k-(1-\alpha) f$, and the lower bound is $x=-k$, which gives $y=k$.
} 
Proposition 3. Imposing or tightening a binding UL constraint has no effect on aggregate output if $c_{f}=c$; it lowers (raises) aggregate output if $c_{f}>(<) c$.

Proof. When the constraint binds, aggregate output is $\alpha(k+x(\alpha))+[f-x(\alpha)]=y(\alpha)+f$, which changes with $\alpha$ at the rate $y^{\prime}(\alpha)$. The denominator in (17) is negative, by the secondorder necessary condition and Assumption 1, so the sign of $y^{\prime}(\alpha)$ is the opposite of the sign of $c_{f}-c$. This shows that tightening a binding UL constraint has the stated effect. Starting from the value of $\alpha$ at which the constraint begins to bind shows that imposing a constraint also has the stated effect.

When marginal costs are equal, Proposition 3 implies that $y^{\prime}(\alpha)=0$. By definition, $y^{\prime}(\alpha)=k+x(\alpha)+(\alpha-1) x^{\prime}(\alpha)=0$ so $x^{\prime}(\alpha)=\frac{k+x(\alpha)}{1-\alpha}>0$. An immediate implication is that a tighter constraint induces more capacity acquisition.

Corollary 1. Suppose that $c_{f}=c$. Imposing or tightening a binding UL constraint raises the amount of capacity acquired by the dominant firm.

One way to understand Corollary 1 is to compare three simple strategies for complying with the UL constraint. Absent a UL constraint, the dominant firm would not buy or sell capacity when $c_{f}=c$, so it would produce $q(0)$. Now consider a binding UL constraint, so $q(0)<\alpha k$. The simplest way for the dominant firm to comply with the constraint is to increase output so that $q=\alpha k>q(0)$. A second possible strategy is to sell some capacity to the fringe, so $x<0$, and then produce $q=\alpha(k+x)$. A third possibility is to acquire capacity and use it all; that is, acquire and employ the amount $x>0$ such that $q=\alpha(k+x)=q(0)+x$. The first two strategies increase aggregate output, while the third leaves aggregate output unchanged. This means that the first two reduce aggregate profit (and the dominant firm's profit) relative to the benchmark case, while the third leaves aggregate profit unchanged. ${ }^{19}$ The dominant firm buys capacity now because the

\footnotetext{
${ }^{19}$ If the dominant firm acquires $x$ and satisfies the UL constraint, its profit from capacity acquisition is $[P(\alpha(k+x)-x+f)-c][\alpha(k+x)-x]$. Absent the UL constraint, its profit is $[P(q+f)-c] q$. The latter is maximized at $q(0)$, so the former is maximized when $\alpha(k+x)-x=q(0)$.
} 
cost of purchasing any given amount is lower when there is a binding UL constraint. ${ }^{20}$ As $\alpha$ rises, even more capacity must be acquired to keep aggregate output unchanged from the benchmark case.

An increase in fringe marginal cost would lower the acquisition price of capacity, all else equal. The dominant firm would then have a heightened incentive to acquire capacity, and aggregate output will drop. If the fringe marginal cost falls, the dominant firm will acquire less capacity and aggregate output will then rise.

To see the impact of tightening the constraint formally, it is again helpful to think in terms of the variable component of aggregate output, $y=\alpha(k+x)-x$. The dominant firm's effective marginal cost of $y$ is $\tilde{c} \equiv \frac{c_{f}-\alpha c}{1-\alpha}$ (see (13)); it changes at the rate

$$
\frac{\partial \tilde{c}}{\partial \alpha}=\frac{c_{f}-c}{(1-\alpha)^{2}}
$$

as $\alpha$ rises. Thus, $\tilde{c}$ is increasing (decreasing) in $\alpha$ if $c_{f}>(<) c$. This means that tightening a binding constraint raises the effective marginal cost of $y$ if the dominant firm is more efficient, which increases the firm's incentive to reduce $y$. Aggregate output, which equals $y+f$, therefore falls.

It is noteworthy that tightening the constraint reduces output precisely when the dominant firm has lower production costs. The acquisition would benefit consumers if the authority could induce the dominant firm to employ enough of the acquired capacity; however, Proposition 3 shows that a use-or-lose provision actually makes matters worse for consumers by inducing the dominant firm to acquire and hoard even more capacity.

Dominant firms are often more efficient than fringe firms, but there are situations in which the fringe firms have lower costs. In such cases, tightening the UL constraint benefits consumers, although it does not necessarily increase total surplus, as we show in Section 4 .

At this point, one might ask whether the precise form of the UL provision is important for the results. We have so far considered a UL provision that requires using a certain

\footnotetext{
${ }^{20}$ The constraint commits the dominant firm to produce a certain amount of output, which lowers the purchase price for given $x$.
} 
minimum fraction of one's capacity. A simple alternative would require that the dominant firm produce at least $q^{*}$, where $q^{*}>q(0)$. In other words, this alternative would impose an absolute constraint $\left(q \geq q^{*}\right)$ rather than a relative constraint $(q \geq \alpha(k+x))$.

Suppose that $c=c_{f}$. The dominant firm will not purchase $x$ such that $q(x)>q^{*}$. (The firm's unconstrained optimum is to purchase zero and its profit function is strictly quasiconcave.) Given that the constraint will bind, the dominant firm's profit from acquiring $x$ is

$$
q^{*}\left[P\left(q^{*}+f-x\right)-c\right]-x\left[P\left(q^{*}+f-x\right)-c_{f}\right]=\left[q^{*}-x\right]\left[P\left(q^{*}+f-x\right)-c\right] .
$$

This is the same form as (14), with $c=c_{f}$ and with $q^{*}-x$ taking the place of $y$. Thus, the dominant firm will again undo the effect of the constraint by purchasing capacity. In particular, profit is maximized when $q^{*}-x=q(0)$ so $x=q^{*}-q(0)>0$. This shows that the precise form of the UL provision is not critical.

Another question is whether the dominant firm could evade the UL constraint by signing supply agreements whereby fringe firms agree to supply some of its output. For example, if a UL provision gave the dominant firm credit for fringe capacity used as part of a supply agreement, this would be another way to satisfy the constraint. It would differ from acquisition only to the extent that marginal costs differed between the dominant firm and the fringe. Of course, a more-efficient dominant firm would prefer to acquire capacity rather than have it operated by a less-efficient fringe firm. A related question is whether the cost of using a particular unit of capacity should be specific to the firm or to the capacity. Suppose that the cost of using a particular unit of capacity were the same for all users, but there were differences across units. Then, the analysis is just like the analysis above for the case of equal marginal costs since the price-cost margin for a particular unit of capacity will be equal for the dominant firm and the fringe. ${ }^{21}$

\footnotetext{
${ }^{21}$ The acquisition price would now differ across units, but the dominant firm would be indifferent among different units that promise the same price-cost margin.
} 


\section{Welfare}

When the dominant firm and the fringe firms have equal marginal costs, Proposition 3 implies that tightening the UL provision does not affect total surplus because the dominant firm adjusts its capacity acquisition so as to leave aggregate output and aggregate cost unchanged. The UL provision does affect total surplus when $c \neq c_{f}$ since aggregate output changes, and the allocation of production across firms also matters.

When UL binds, total surplus can be written as

$$
\begin{array}{r}
\tilde{T S}(\alpha) \equiv \int_{0}^{\alpha(k+x(\alpha))+f-x(\alpha)} P(z) d z-c \alpha[k+x(\alpha)]-c_{f}[f-x(\alpha)] \\
=\int_{0}^{y(\alpha)+f} P(z) d z-c y(\alpha)-c_{f} f+\left[c_{f}-c\right] x(\alpha),
\end{array}
$$

since $y(\alpha)=\alpha(k+x(\alpha))-x(\alpha)$. As $\mathrm{UL}$ is tightened, total surplus changes at the rate

$$
\tilde{T S}(\alpha)=\underbrace{y^{\prime}(\alpha)[P-c]}_{\begin{array}{c}
\text { Output } \\
\text { Effect }
\end{array}}+\underbrace{x^{\prime}(\alpha)\left[c_{f}-c\right]}_{\begin{array}{c}
\text { Production } \\
\text { Cost Effect }
\end{array}} .
$$

Aggregate output changes at the rate $y^{\prime}(\alpha)$, which brings a benefit of $P-c$ per unit of output (the "output effect"). The dominant firm's net purchase rises at the rate $x^{\prime}(\alpha)$ and production costs fall by $c_{f}-c$ per unit purchased (the "production cost effect").

The output and production cost effects may have opposite signs, which makes it difficult to sign the total surplus effects in general. However, it is possible to understand the forces at work when the UL constraint is just binding and the firms' costs are similar.

By definition of $y(\alpha)$, we have

$$
y^{\prime}(\alpha)=k+x(\alpha)+(\alpha-1) x^{\prime}(\alpha) \Rightarrow x^{\prime}(\alpha)=\frac{k+x(\alpha)-y^{\prime}(\alpha)}{1-\alpha}
$$

Let $\alpha^{*}$ be the value of $\alpha$ at which the constraint just begins to bind. Substituting (17) and (22) into (21) and evaluating at $\alpha^{*}$ yields 


\begin{tabular}{|c|c|c|c|c|}
\hline \multirow[b]{2}{*}{$\begin{array}{l}\text { DF cost } \\
\text { advantage } \\
\left(c_{f}>c\right)\end{array}$} & \multicolumn{2}{|c|}{ Low excess capacity $(\mathrm{k}<\hat{\mathrm{k}})$} & \multicolumn{2}{|c|}{ High excess capacity $(\mathrm{k}>\hat{\mathrm{k}})$} \\
\hline & $\begin{array}{l}\text { Total surplus: } \\
\text { Consumer surplus: }\end{array}$ & $\begin{array}{l}+ \\
-\end{array}$ & $\begin{array}{l}\text { Total surplus: } \\
\text { Consumer surplus: }\end{array}$ & - \\
\hline $\begin{array}{l}\text { Fringe cost } \\
\text { advantage } \\
\left(c_{\mathrm{f}}<\mathrm{c}\right)\end{array}$ & $\begin{array}{l}\text { Total surplus: } \\
\text { Consumer surplus }\end{array}$ & $\begin{array}{l}- \\
+\end{array}$ & $\begin{array}{l}\text { Total surplus: } \\
\text { Consumer surplus: }\end{array}$ & $\begin{array}{l}+ \\
+\end{array}$ \\
\hline
\end{tabular}

Figure 1: Surplus effects of tightening a just-binding UL constraint when costs are similar.

$$
\operatorname{sign}\left\{\tilde{T S^{\prime}}\left(\alpha^{*}\right)\right\}=\operatorname{sign}\{\underbrace{\frac{(P-c)\left(c_{f}-c\right)}{\left(1-\alpha^{*}\right)^{2}\left(P^{\prime \prime} y+2 P^{\prime}\right)}}_{\begin{array}{c}
\text { Output } \\
\text { Effect }
\end{array}}+\underbrace{\frac{\left(k+x\left(\alpha^{*}\right)-y^{\prime}\left(\alpha^{*}\right)\right)\left(c_{f}-c\right)}{1-\alpha^{*}}}_{\begin{array}{c}
\text { Production } \\
\text { Cost Effect }
\end{array}}\} .
$$

When $c_{f} \approx c, y^{\prime}\left(\alpha^{*}\right) \approx 0$ (by $\left.(17)\right)$ and $x\left(\alpha^{*}\right) \approx 0$, so the production cost effect has the same sign as $c_{f}-c$, while the output effect has the opposite sign. The sign of $\tilde{T S^{\prime}}\left(\alpha^{*}\right)$ turns on which effect is larger. When $\alpha=\alpha^{*}$ and $c_{f} \approx c$, aggregate output is approximately $q(0)+f$. Rewriting $(23)$ gives

$$
\operatorname{sign}\left\{\tilde{T} S^{\prime}\left(\alpha^{*}\right)\right\}=\operatorname{sign}\left\{\frac{\left(c_{f}-c\right)}{1-\alpha^{*}}\left[\frac{P-c}{\left(1-\alpha^{*}\right)\left(P^{\prime \prime} q(0)+2 P^{\prime}\right)}+k\right]\right\} .
$$

The first term in square brackets is negative. It follows that there exists a value, $\hat{k}$, such that the output effect dominates if $k<\hat{k}$, and the production cost effect dominates if $k>\hat{k}$.

Figure 1 summarizes the total surplus effects and also records the consumer surplus effects for comparison. ${ }^{22}$ A key point is that the impact of tightening the UL constraint depends critically on key parameters (cost differences and the dominant firm's capacity), in ways that make policy prescriptions difficult.

\footnotetext{
${ }^{22}$ Each of the four cases is feasible with linear demand, for example.
} 


\section{Oligoply}

Many markets that are subject to use-or-lose provisions have more than one large firm. For instance, an airline market may have two or more major carriers. It is therefore important to study the case of multiple dominant firms as well. We now focus on a market in which two (unconstrained) firms with market power face a competitive fringe. We refer to this market structure as "duopoly." (The extension to $N$-firm oligopoly requires regularity conditions analogous to those for the two-firm case and is straightforward.) All output and capacity variables are now indexed by $i$ for firm $i=1,2$.

Absent a UL provision, there are hoarding incentives again, but they are tempered by free-riding as each duopolist prefers that the other one acquire fringe capacity and keep it idle. Accordingly, duopolists have less incentive (in aggregate) to acquire capacity than does a single dominant firm. With a binding UL provision, however, the effects are much the same as with a single dominant firm. In particular, tightening the use-or-lose constraint may again raise or lower aggregate output and total surplus.

As a benchmark, suppose that there is no UL provision in force. Given net purchases $x_{1}$ and $x_{2}$, the fringe will produce $f-\left(x_{1}+x_{2}\right)$, and firm $i$ will produce a quantity denoted $q_{i}\left(x_{1}+x_{2}\right)$. Now let

$$
\Phi_{1}\left(x_{1}\right) \equiv\left[P\left(q_{1}\left(x_{1}+x_{2}\right)+q_{2}\left(x_{1}+x_{2}\right)+f-x_{1}-x_{2}\right)-c_{1}\right]\left[q_{1}\left(x_{1}+x_{2}\right)-x_{1}\right]+\left(c_{f}-c_{1}\right) x_{1}
$$

denote firm 1's profit from paying the market-clearing price for $x_{1}$ units, and then producing optimally, given that firm 2 acquires $x_{2}$ and produces $q_{2}\left(x_{1}+x_{2}\right) .{ }^{23}$ The rate of change is

$\Phi_{1}^{\prime}\left(x_{1}\right)=\left[P-c_{1}\right]\left[q_{1}^{\prime}\left(x_{1}+x_{2}\right)-1\right]+P^{\prime}\left[q_{1}^{\prime}\left(x_{1}+x_{2}\right)+q_{2}^{\prime}\left(x_{1}+x_{2}\right)-1\right]\left[q_{1}\left(x_{1}+x_{2}\right)-x_{1}\right]$

$$
+c_{f}-c_{1} .
$$

\footnotetext{
${ }^{23}$ We assume that bilateral trades between firms 1 and 2 are not permitted; if they were, one duopolist could acquire all of the other's capacity. It is plausible that antitrust authorities would more likely block a merger between dominant duopolists than an exchange of capacity between a duopolist and a fringe firm.
} 
Rearranging terms gives

$$
\begin{array}{r}
\Phi_{1}^{\prime}\left(x_{1}\right)=\left\{P-c_{1}+P^{\prime} q_{1}\left(x_{1}+x_{2}\right)\right\}\left[q_{1}^{\prime}\left(x_{1}+x_{2}\right)-1\right]+P^{\prime} q_{2}^{\prime}\left(x_{1}+x_{2}\right) q_{1}\left(x_{1}+x_{2}\right) \\
-P^{\prime}\left[q_{1}^{\prime}\left(x_{1}+x_{2}\right)+q_{2}^{\prime}\left(x_{1}+x_{2}\right)-1\right] x_{1}+c_{f}-c_{1} .
\end{array}
$$

At an interior maximum of the production game, the term in braces is zero. This leaves us with

$$
(2 £)_{1}^{\prime}\left(x_{1}\right)=P^{\prime} q_{2}^{\prime}\left(x_{1}+x_{2}\right) q_{1}\left(x_{1}+x_{2}\right)-P^{\prime}\left[q_{1}^{\prime}\left(x_{1}+x_{2}\right)+q_{2}^{\prime}\left(x_{1}+x_{2}\right)-1\right] x_{1}+c_{f}-c_{1} .
$$

There is a clear difference between a duopoly and a market with a single dominant firm. When $c_{f}=c_{1}$ and $x_{1}=0$, we have

$$
\Phi_{1}^{\prime}(0)=P^{\prime} q_{2}^{\prime}\left(x_{1}+x_{2}\right) q_{1}\left(x_{1}+x_{2}\right)<0 .
$$

It follows that firm 1 will sell capacity in the absence of a UL provision. Whereas a single dominant firm will neither buy nor sell, a duopolist will sell because it bears only part of the loss from the resulting increase in aggregate output.

Now consider a UL constraint that binds for both firms. In the capacity-acquisition stage, the firms again submit orders and trades take place at the price $P-c_{f}$. Let $y_{i} \equiv$ $\alpha\left(x_{i}+k_{i}\right)-x_{i}$ be firm $i$ 's net contribution to aggregate output. Firm $i$ faces an acquisition problem analogous to that of a single dominant firm in (14):

$$
\max _{k_{i} \geq y_{i} \geq \alpha k_{i}-(1-\alpha)\left(f-x_{j}\right)} P\left(y_{1}+y_{2}+f\right) y_{i}-\frac{c_{f}-\alpha c_{i}}{1-\alpha} y_{i}-\frac{c_{i}-c_{f}}{1-\alpha} \alpha k_{i} .
$$

The first-order conditions now amount to:

$$
\phi_{i}\left(y_{1}, y_{2}, \alpha, c_{i}, c_{f}\right) \equiv P^{\prime} y_{i}+P-\frac{c_{f}-\alpha c_{i}}{1-\alpha}=0 ; i=1,2
$$

Let $\left(y_{1}(\alpha), y_{2}(\alpha)\right)$ denote the solution to (31) for given marginal costs. The second-order necessary condition for firm $i$ is

$$
\phi_{i i}\left(y_{1}, y_{2}, \alpha, c_{i}, c_{f}\right)=P^{\prime \prime} y_{i}+2 P^{\prime} \leq 0 ; \quad i=1,2
$$


Meanwhile,

$$
\phi_{i j}\left(y_{1}, y_{2}, \alpha, c_{i}, c_{f}\right)=P^{\prime \prime} y_{i}+P^{\prime} ; \quad i=1,2 ; i \neq j
$$

The case of equal marginal costs is again straightforward. If $c_{f}=c_{i}$, the first-order condition simplifies as

$$
P^{\prime} y_{i}+P-c_{i}=0 ; \quad i=1,2 .
$$

The firms now adjust their capacity purchases in response to the UL constraint in such a way that aggregate output is unchanged. As with a single dominant firm, the binding constraint makes it more likely that a dominant firm will acquire capacity.

The next result imposes a condition that is slightly stronger than the second-order necessary condition. The condition requires that demand not be too convex, and it implies that $\phi_{11} \phi_{22}<\phi_{12} \phi_{21}$, which is sufficient for the solution to the first-order conditions to be asymptotically stable.

Proposition 4. If $P^{\prime \prime}\left[y_{1}+y_{2}\right]+3 P^{\prime}<0$, tightening the UL constraint lowers (raises) aggregate output if the duopolists have lower (higher) marginal costs than the fringe firms.

Proof. Differentiating the firms' first-order conditions with respect to $\alpha$ yields two equations in $y_{1}^{\prime}(\alpha)$ and $y_{2}^{\prime}(\alpha)$. Solving gives

$$
y_{i}^{\prime}(\alpha)=\frac{-\left(c_{i}-c_{f}\right) \phi_{j j}+\left(c_{j}-c_{f}\right) \phi_{i j}}{(1-\alpha)^{2}\left(\phi_{11} \phi_{22}-\phi_{12} \phi_{21}\right)} ; \quad i=1,2 ; i \neq j
$$

The impact on aggregate output of tightening the UL constraint is therefore

$$
\begin{aligned}
y_{1}^{\prime}(\alpha)+y_{2}^{\prime}(\alpha) & =\frac{-\left(c_{1}-c_{f}\right)\left[\phi_{22}-\phi_{21}\right]-\left(c_{2}-c_{f}\right)\left[\phi_{11}-\phi_{12}\right]}{(1-\alpha)^{2}\left(\phi_{11} \phi_{22}-\phi_{12} \phi_{21}\right)} . \\
& =\frac{2 c_{f}-\left(c_{1}+c_{2}\right)}{(1-\alpha)^{2}\left(P^{\prime \prime}\left[y_{1}+y_{2}\right]+3 P^{\prime}\right)}
\end{aligned}
$$

Since $P^{\prime \prime}\left[y_{1}+y_{2}\right]+3 P^{\prime}<0$, tightening the constraint lowers (raises) aggregate output when both duopolists have lower (higher) marginal costs than the fringe firms do. 
This result shows that total surplus does not change when the UL provision is tightened, if all firms have the same marginal cost. As with a single dominant firm, the firms buy more capacity (or sell less) as $\alpha$ rises.

It is also possible to show similarities for general marginal costs. When the UL constraint binds for both firms in equilibrium, total surplus can be expressed as

$$
T S(\alpha) \equiv \int_{0}^{y_{1}(\alpha)+y_{2}(\alpha)+f} P(z) d z-c_{1} y_{1}(\alpha)-c_{2} y_{2}(\alpha)-c_{f} f+\left[c_{f}-c_{1}\right] x_{1}(\alpha)+\left[c_{f}-c_{2}\right] x_{2}(\alpha)
$$

As UL is tightened, total surplus changes at the rate

$$
T S^{\prime}(\alpha)=y_{1}^{\prime}(\alpha)\left[P-c_{1}\right]+y_{2}^{\prime}(\alpha)\left[P-c_{2}\right]+x_{1}^{\prime}(\alpha)\left[c_{f}-c_{1}\right]+x_{2}^{\prime}(\alpha)\left[c_{f}-c_{2}\right]
$$

Since $x_{i}(\alpha)=\frac{\alpha k_{i}-y_{i}(\alpha)}{1-\alpha}$, we have

$$
x_{i}^{\prime}(\alpha)=\frac{\left(k_{i}-y_{i}^{\prime}(\alpha)\right)(1-\alpha)+\alpha k_{i}-y_{i}(\alpha)}{(1-\alpha)^{2}}=\frac{k_{i}+x_{i}(\alpha)-y_{i}^{\prime}(\alpha)}{1-\alpha} .
$$

It follows that

$$
\begin{array}{r}
T S^{\prime}(\alpha)=y_{1}^{\prime}(\alpha)\left[P-c_{1}\right]+y_{2}^{\prime}(\alpha)\left[P-c_{2}\right]+\frac{k_{1}+x_{1}(\alpha)-y_{1}^{\prime}(\alpha)}{1-\alpha}\left[c_{f}-c_{1}\right] \\
+\frac{k_{2}+x_{2}(\alpha)-y_{2}^{\prime}(\alpha)}{1-\alpha}\left[c_{f}-c_{2}\right] .
\end{array}
$$

Again, the results are reminiscent of those for a single dominant firm. Equation (35) tells us that $y_{1}^{\prime}(\alpha)+y_{2}^{\prime}(\alpha)=0$ if $c_{1}=c_{2}=c_{f}$, so $T S^{\prime}(\alpha)=0$, as noted above. In other words, the duopolists undo the effect of the use-or-lose provision. When marginal costs differ, we have the same pattern of opposing effects as before, with the tradeoff for each duopolist being the same as it is for a single dominant firm. In that sense, the main results are robust to the inclusion of a second firm with market power.

\section{Related Literature}

Capacity acquisition and use-or-lose provisions are the two essential elements of the current paper. Several papers have incorporated one of these features. Kala Krishna (1993) was 
interested in whether a dominant firm would outbid potential entrants for capacity that came available exogenously. She found that the dominant firm would only acquire the last unit of capacity in a sequential auction against equally efficient entrants. ${ }^{24}$ We consider a one-time acquisition of existing capacity and get similar qualitative results when there is no use-or-lose provision. As noted, the results change with a use-or-lose provision.

Michael H. Riordan (1998) also examined capacity acquisition by a dominant firm facing a competitive fringe. In his model, the acquired capacity is in an upstream market, and his focus is on the effects of vertical integration. (One could interpret capacity in our model as upstream capacity.) He found that an exogenous increase in the initial level of integration lowers consumer welfare and has ambiguous effects on total welfare.

Capacity acquisition was also the focus of Ian Gale and Daniel P. O'Brien (2001), which studied a dominant firm and a competitive fringe producing in two markets. ${ }^{25}$ The basic model of capacity acquisition and production parallels the model here, but the focus of the current paper is different because of the use-or-lose provision.

Other papers have examined variants of the use-or-lose provision. For instance, Ian Gale (1993) considered a noncooperative joint venture, which essentially involved a use-or-lose provision that required firms to use 100 percent of their capacity. (Rivals were permitted to use a firm's unused capacity.) We consider a range of requirements here, and the purchase or sale of capacity are also permitted.

Gautam Gowrisankaran and Thomas J. Holmes (2004) (henceforth GH) also consider a market with a dominant firm and a competitive fringe. Whereas we focus on one method for dealing with concentration, GH focus on the evolution of concentration itself. In GH, all firms have access to the same neo-classical production function, and a firm's short-run marginal cost is decreasing in its capital, so the dominant firm has a lower marginal cost simply by virtue of having more capital than the fringe firms do. Firms may buy and sell

\footnotetext{
${ }^{24}$ The dominant firm acquired the last unit in her model because of the discreteness of capacity.

${ }^{25}$ Some of the existing capacity was productive in both markets. The motivation for that paper was the Specialized Mobile Radio industry in which some frequencies were used for paging services but others could be used for both paging and cellular telephony.
} 
capital, but there is no scope for idle capacity.

GH consider both a single-period model and an infinite-horizon model. Their results for a single period mirror some of our findings for the benchmark case in which use-or-lose provisions are not imposed. For example, GH find that when the dominant firm and fringe firms start with positive levels of capital, the dominant firm will buy some capital from the fringe in equilibrium. This finding is consistent with ours in that the dominant firm in GH has a lower marginal cost in equilibrium than fringe firms do. The results of the infinite-horizon model are also germane since GH find that the industry need not evolve to perfect competition or monopoly. As such, the question we address - the efficacy of use-or-lose provisions — remains relevant.

\section{Conclusion}

This paper has studied the imposition of a use-or-lose provision on a dominant firm in an industry with limited capacity. Although a use-or-lose provision encourages capacity usage, it also changes the dominant firm's incentive to acquire capacity from fringe firms. The main insight of the paper is that the ability to acquire capacity may alter the impact of a use-or-lose provision in unexpected ways. If the dominant firm is more efficient than fringe firms, a use-or-lose provision induces it to acquire capacity from the fringe, but the increase in its own output does not offset the reduction in the output of the fringe, so aggregate output falls. Total surplus may rise or fall. In the event that fringe firms are more efficient, aggregate output will rise, but the effect on total surplus is again ambiguous.

The model here provides a point of departure for the evaluation of use-or-lose provisions. The insights apply to a range of industries in which firms may face restrictions on capacity usage while being free to buy and sell capacity. The stated rationale for use-or-lose provisions has been to encourage output expansion by preventing capacity hoarding and encouraging firms with market power to use their capacity. Our results suggest that use-orlose provisions do not necessarily provide these benefits. In cases where the dominant firm 
and the fringe have comparable cost structures, the use-or-lose provision has essentially no effect on aggregate output or welfare. When the dominant firm is much more efficient than the fringe, one might anticipate a large, positive effect, yet aggregate output will fall in this case. Total surplus may still rise, but by less than if the dominant firm simply expanded its output to satisfy the constraint. The welfare effects of use-or-lose provisions are ambiguous in general, and they depend on parameters in ways that make policy prescriptions difficult, so authorities should be careful when imposing them. 


\section{References}

Ausubel, Lawrence M., and Raymond J. Deneckere, 1989, "Reputation in Bargaining and Durable Goods Monopoly," Econometrica 57, 511-531.

European Commission, 2005, "Merger Remedies Study," Competition Directorate-General.

Gale, Ian, 1994, "Price Competition in Noncooperative Joint Ventures," International Journal of Industrial Organization, 12, 53-69.

Gale, Ian, and Daniel P. O'Brien, 2001, "The Antitrust Implications of Capacity Reallocation by a Dominant Firm," The Journal of Industrial Economics, XLIX, 137-160.

Gowrisankaran, Gautam, and Thomas J. Holmes, 2004, "Industry Concentration: Results From the Dominant Firm Model," RAND Journal of Economics, 35, 561-82.

Krishna, Kala., 1993, "Auctions with Endogenous Valuations: The Persistence of Monopoly Revisited," American Economic Review, 83, 147-160.

Motta, Massimo, Michele Polo, and Helder Vasconcelos, 2007, "Merger Remedies in the European Union: An Overview," Antitrust Bulletin, 52, 603-631.

Papandropoulos, Penelope, and Alessandro Tajana, 2006, "The Merger Remedies StudyIn Divestiture We Trust?" European Competition Law Review, 8, 443-454.

Riordan, Michael H., 1998, "Anticompetitive Vertical Integration by a Dominant Firm," American Economic Review, 88, 1232-48.

U.S. Federal Trade Commission, 1999, "A Study of the Commission's Divestiture Process," Prepared by the Staff of the Bureau of Competition. 